\title{
E्己̌çấ。 Espaços Escolares Indígenas no Brasil: políticas, ações e atores envolvidos
}

\author{
Nauíra Zanardo Zanin' \\ Ivone Maria Mendes Silva' \\ Maria Silvia Cristofoli
}

'Universidade Federal da Fronteira Sul (UFFS), Erechim/RS - Brasil

RESUMO - Espaços Escolares Indígenas no Brasil: políticas, ações e atores envolvidos. Este artigo tem como escopo problematizar os espaços escolares indígenas no Brasil, voltando nossa atenção para diferentes parâmetros que têm pautado as intervenções arquitetônicas e a repercussão delas em comunidades indígenas. A partir dos documentos oficiais, situamos o tema na legislação e nos documentos normativos e, além disso, analisamos projetos arquitetônicos e publicações na mídia. Os achados apontam que a infraestrutura escolar ainda se põe como desafio para o Ministério da Educação e que há necessidade de ampliar e aprimorar as iniciativas voltadas à qualificação desses espaços, bem como os processos de participação de grupos indígenas nas instâncias decisórias que possibilitam a construção das políticas e as ações derivadas.

Palavras-chave: Espaços Escolares. Intervenções Arquitetônicas. Políticas Educacionais. Diversidade Sociocultural. Sujeitos Escolares Indígenas.

ABSTRACT - Indigenous School Physical Environment in Brasil: policies, actions and actors involved. This article aims to problematize the indigenous school physical environment in Brasil focusing on different parameters that have guided the architectonic interventions and their repercussion in indigenous communities. Based on official documents we have situated the theme on legislation and normative documents, analysed architecture designs and media publications. The findings indicate that the school infrastructure remmains a challenge to the Education Ministry, and that it is necessary to expand and enhance the iniciatives concerning the improvement of those environments, along with the participation processes of indigenous groups in decision-making instances that enable the development of policies and subsequent actions. Keywords: School Physical Environment. Architectural Interventions. Educational Policies. Socio-Cultural Diversity. Indigenous School Subjects. 
Espaços Escolares Indígenas no Brasil

\section{Introdução}

O Brasil é um país de dimensões continentais, caracterizado por abrigar, mesmo antes de sua formação como nação, grupos étnico-culturais diversos e com tradições e modos de vida específicos. Essa diversidade, apesar de ser exaltada como um dos aspectos que selam a singularidade nacional, tem sido "[...] historicamente tratada de forma discriminatória” em nossa sociedade (Gomes, 2007, p. 31), com repercussões negativas em muitos planos.

As iniciativas educacionais em comunidades indígenas não contrariam essa tendência. A princípio, tinham perspectiva integracionista e assimilatória, mas somente com a Constituição Federal de 1988 - CF/88 - (Brasil, 1988) os indígenas começaram a ter seus direitos reconhecidos. Mais recentemente, passou a ser da alçada das políticas educacionais abordar essa educação de forma diferenciada, respeitando as especificidades dessas comunidades. Com o acesso a uma escola específica e particularizada, os povos indígenas passaram a ver a educação como uma forma de assegurar seus direitos, por possibilitar a eles a ampliação do diálogo com a sociedade nacional e a afirmação de suas identidades étnicas (Brand; Calderoni, 2012; Altini et al., 2014).

Se, por um lado, é indiscutível que avanços no processo de democratização do ensino foram alcançados no plano do acesso, com a possibilidade de grupos até então excluídos da escola poderem frequentá-la, por outro, no entanto, mostra-se evidente que muitas das relações e dos processos que ocorrem no interior dessa instituição são excludentes para determinados alunos, colocando em questão suas chances de nela permanecerem ou de perceberem como significativas as experiências escolares que tiveram oportunidade de ali construir (Boto, 2005; Santos; Nogueira, 1999).

Como diversas ações legais e políticas levadas a cabo para o cumprimento dos direitos desses grupos surtiram efeito no campo do acesso, a expectativa geral é de que isso também se efetive no combate às outras formas de exclusão remanescentes que, conforme destaca Boto (2005), não se reduzem àquilo que ocorre no campo do ensino-aprendizagem. Essa autora lembra que o debate sobre democratização do ensino passa também pela análise dos “[...] projetos pedagógicos que estão na base do firmamento de cada cultura educativa em sua especificidade" (Boto, 2005, p. 794). Ao problematizar as possíveis articulações entre educação e direitos humanos, a autora tece considerações sobre o que seria uma "escola de boa qualidade" nos tempos que correm, ao que ela mesma responde:

[...] antes de tudo, uma escola de boa qualidade ainda é, pela lei e pelo direito consuetudinário, dever de Estado e direito subjetivo do cidadão. Que escola é essa? Se possível, a mesma para todos, e - como bem sublinhou Azanha (1987) - isso se deve, antes, a uma inegociável exigência política do que a argumentos provenientes do âmbito pedagógico. Mais do que isso, a escola que projetamos 
- como algures observou Snyders - será aquela que nos possibilite 'desfrutar - em nosso foro íntimo - de tudo o que deveria pertencer à Humanidade inteira’ [...] (Boto, 2005, p. 795).

Não obstante, podemos ponderar se essa exigência política de que nos fala Boto (2005) tem se traduzido em medidas capazes de ampliar, de fato, a possibilidade de as populações marginalizadas (urbanas e rurais), os grupos indígenas e os quilombolas, dentre outros historicamente excluídos, alcançarem uma educação de qualidade sem que, para isso, tenham suas diferenças transformadas em estigmas ou sua condição de co-construtores dos processos escolares, sociais e políticos dos quais participam negada (Arroyo, 2012).

Em relação a isso, Gomes (2007, p. 32) afirma que, ainda que caminhemos para a "[...] transformação do sistema educacional público em um sistema inclusivo, democrático e aberto à diversidade", graças a iniciativas desenvolvidas no âmbito pedagógico e também no político, é inquestionável a necessidade de promover "[...] ações articuladas entre o Estado, a comunidade, as escolas e os diversos movimentos sociais" que sejam capazes de se aproximar das necessidades e dos interesses desses grupos. O que não se pode perder de vista, ressalta a autora, é que as ações devem contemplar as diferentes dimensões atinentes ao processo educacional, incluindo a organização dos tempos e espaços escolares, as tradições culturais específicas e seus efeitos na relação que os indivíduos estabelecem com os processos de ensino e aprendizagem, bem como outros fatores que possam interferir na dinâmica escolar, como a(s) língua(s) falada(s) em sala de aula, por exemplo.

Segundo Arruti (1997, p. 8), as reflexões sobre o assunto devem contemplar "[...] a retomada da história dessas populações e a análise de sua realidade atual”. Raciocínio semelhante é apresentado por Cury (2008, p. 210):

Se a inserção do direito à educação tornou-se, hoje, um princípio e uma norma do ordenamento jurídico brasileiro e se a atual realidade indica uma inclusão excludente e seletiva, então é preciso verificar também, na ordem legal, como o ontem o inscreveu, até por uma razão de ordem processual e de memória histórica. Essa leitura pode tanto propiciar uma aproximação do processo histórico de cujo peso ainda hoje vemos as consequências, quanto pode nos permitir uma abertura para novas possibilidades.

Imbuídas desse pensamento, dedicamo-nos ao levantamento de documentos oficiais e de outros materiais em circulação no Brasil que expressam preocupação com a questão da educação escolar indígena e, mais especificamente, com os espaços escolares que têm sido criados ou destinados a essa parcela da população.

Antes de abordar a temática dos espaços escolares e as ações do poder público propriamente ditas, cumpre salientar que, no ordenamento legal brasileiro, a educação se situa no campo das políticas sociais. Portanto, entendemos que falar em políticas públicas é falar, prin- 
Espaços Escolares Indígenas no Brasil

cipalmente, nas ações do Estado, pois, embora envolvam vários atores e níveis de decisão, são materializadas através dos governos (Souza, 2006). Quanto à política educacional voltada para os povos indígenas, Oliveira e Nascimento (2012) chamam a atenção de que ela se situa no âmbito das políticas indigenistas do Estado e, portanto, expressam a natureza da relação que o Estado pretende estabelecer com tais povos.

Na educação, podemos considerar que, nessa perspectiva, as políticas educacionais serão a expressão da "[...] multiplicidade e da diversidade da política educacional em dado momento histórico" (Vieira, 2007, p. 56). Assim, iniciamos pela consideração de que a educação é um direito social reconhecido na Constituição Federal de 1988 (Brasil, 1988), no seu art. $6^{\circ}$, e de que, enquanto um direito, a educação no Brasil adquiriu o patamar de direito público subjetivo, possibilitando que todos aqueles a quem esse direito for negado possam acionar o poder público para garanti-lo (Duarte, 2004).

Nas últimas décadas, houve avanços significativos na garantia (ao menos na legislação) de uma série de direitos e de respeito à diversidade cultural, étnica e social. Dentre esses grupos sempre existentes em nossa sociedade, mas, por muito tempo, à margem de direitos e políticas públicas sociais, situamos os indígenas. Foi também a partir da CF/88 que direitos indígenas foram legitimados, sendo reconhecidas novas formas de relação entre o Estado brasileiro e os povos indígenas. Essas relações são pautadas "[...] pelo reconhecimento, pela valorização e manutenção da sociodiversidade indígena” (Conferência de Educação Escolar Indígena, 2009, p. 2).

Tomando como referência o ordenamento legal e normativo brasileiro, devemos destacar que é somente a partir da última década do século XX que podemos identificar ações mais efetivas em relação à Educação Escolar Indígena (EEI), a qual passou a ser, também, de responsabilidade do Ministério da Educação e dos sistemas de ensino. Ao mesmo tempo, é preciso enfatizar que, embora seja o governo o principal implementador de políticas, muitas delas surgem a partir de demandas dos diferentes grupos sociais, cabendo aos governos materializá-las. Por esse motivo, incluímos outros documentos que discutem e norteiam a EEI.

No estudo mais detalhado da legislação e da EEI, iniciamos pela Lei de Diretrizes e Bases da Educação Nacional (LDB), Lei no 9.394, de 20 de dezembro de 1996 (Brasil, 1996). Seu art. 78, nas Disposições Gerais, estabelece que a responsabilidade de fomento para o desenvolvimento de programas para oferta de educação bilíngue e intercultural cabe ao sistema de ensino da União com a colaboração das agências federais.

O inciso I do art. 78 da LDB dispõe sobre um dos objetivos da oferta de educação escolar bilíngue e intercultural aos povos indígenas, qual seja o de "[...] proporcionar aos índios, suas comunidades e seus povos, a recuperação de suas memórias históricas; a reafirmação de suas identidades étnicas; a valorização de suas línguas e ciências" (Brasil, 1996, art. 78, inc. I). Ao mesmo tempo, o inciso II do mesmo artigo aponta como objetivo "[...] garantir aos índios, às suas comunidades e 
aos seus povos, o acesso às informações, aos conhecimentos técnicos e científicos da sociedade nacional e das demais sociedades indígenas e não-índias" (Brasil, 1996, art. 78, inc. II). Podemos inferir que, pensando nos espaços escolares, os objetivos apontam para a necessidade de se respeitar as identidades, sem, com isso, privar os povos indígenas dos avanços científicos e tecnológicos, muitas vezes traduzidos, nas escolas, em locais como os laboratórios de informática, por exemplo.

Ainda na década de 1990, anteriormente à LDB, o Decreto no 26, de 4 de fevereiro de 1991 (Brasil, 1991), que dispõe sobre a educação indígena, atribuiu ao Ministério da Educação “[...] a competência para coordenar as ações referentes à Educação Indígena em todos os níveis e modalidades de ensino, ouvida a FUNAI" (Brasil, 1991, art. 1º). Esse decreto também definiu o desenvolvimento das ações educativas a serem realizadas pelas secretarias estaduais e pelos municípios, em uma possível alusão ao que ficou assegurado na Constituição quanto ao regime de colaboração e quanto à divisão das responsabilidades educativas entre os entes (art. 211). Atualmente, as diversas ações voltadas para essa modalidade de educação estão vinculadas à Secretaria de Educação Continuada, Alfabetização, Diversidade e Inclusão (SECADI).

Em um próximo passo, direcionando nosso olhar para os espaços destinados à educação escolar indígena, debruçamo-nos sobre o Decreto no 6.861, de 27 de maio de 2009 (Brasil, 2009), que dispõe sobre a educação escolar indígena e também acerca da organização em territórios etnoeducacionais. Nesse documento, fica expresso, no art. $1^{\mathrm{o}}$, que "A educação escolar indígena será organizada com a participação dos povos indígenas, observada a sua territorialidade e respeitando suas necessidades e especificidades" (Brasil, 2009, art. 1º). Essas escolas, de acordo com o decreto, gozam de prerrogativas especiais para a organização das atividades escolares, respeitando o fluxo das diferentes atividades de cada comunidade (art. 3º). São elementos básicos para a organização, a estrutura e o funcionamento da escola indígena, conforme o art. $4^{\circ}$, incisos I e II, a localização em terras habitadas por comunidades indígenas e o atendimento exclusivo a essas comunidades, cabendo à União o apoio técnico e financeiro para a construção de tais escolas.

O documento final do I Congresso Nacional de Educação Escolar Indígena, realizado em Luziânia (GO), em 2009, também aponta, na segunda parte, as diretrizes para a EEI, a necessidade de reconhecimento, por parte da União, dos Estados e dos Municípios, do cumprimento da oferta de educação de qualidade para os povos indígenas, definindo, dentre outros itens, a infraestrutura adequada.

Dos documentos normativos emanados do Conselho Nacional de Educação, a Resolução CEB nº 3, de 10 de novembro de 1999, fixa as Diretrizes Nacionais para o funcionamento das escolas indígenas e dá outras providências. Nesse documento, é estabelecida a educação escolar indígena na educação básica brasileira, mas, ao mesmo tempo, é reconhecida a necessidade de definição de normas e de ordenamento jurídico próprios (art. $1^{\circ}$ ). No art. $2^{\circ}$ do mesmo documento, são elencados os “[...] elementos básicos para a organização, a estrutura e o funciona- 
Espaços Escolares Indígenas no Brasil

mento da escola indígena”, dentre outros aspectos: “[...] localização em terras habitadas por comunidades indígenas, ainda que se estendam por territórios de diversos Estados ou Municípios contíguos” (inciso I), “[...] exclusividade de atendimento a comunidades indígenas" (inciso II) e “[...] organização escolar própria” (inciso IV) (Conselho Nacional de Educação, 1999). Ainda sobre a organização das escolas indígenas, a resolução considera necessária a participação da comunidade na definição de edificação de escolas que atendam aos interesses das comunidades indígenas (art. 3º, inciso V).

No novo Plano Nacional de Educação (PNE - Lei no 13.005, de 25 de junho de 2014), dentre as diretrizes expressas no art. $2^{\circ}$, aponta-se a melhoria da qualidade da educação (inciso IV). Essa diretriz se relaciona com o previsto na estratégia 26 da meta 7 do PNE, na qual é possível identificar a preocupação com os espaços escolares:

[...] 7.26) consolidar a educação escolar no campo de populações tradicionais, de populações itinerantes e de comunidades indígenas e quilombolas, respeitando a articulação entre os ambientes escolares e comunitários e garantindo: o desenvolvimento sustentável e preservação da identidade cultural; a participação da comunidade na definição do modelo de organização pedagógica e de gestão das instituições, consideradas as práticas socioculturais e as formas particulares de organização do tempo; a oferta bilíngue na educação infantil e nos anos iniciais do ensino fundamental, em língua materna das comunidades indígenas e em língua portuguesa; $a$ reestruturação $e$ a aquisição de equipamentos; a oferta de programa para a formação inicial e continuada de profissionais da educação; e o atendimento em educação especial; [...] (Brasil, 2014, grifos nossos).

Entendendo o termo organização escolar no seu sentido lato, podemos considerar que ele inclui a organização dos espaços físicos e a infraestrutura, bem como, se considerarmos os aspectos da organização pedagógica e dos currículos, o espaço é parte integrante disso (Frago; Escolano, 2001).

A preocupação com os espaços físicos ou com a infraestrutura escolar também está relacionada com a quantidade de escolas. Nos Cadernos Secad, volume 3, intitulado Educação Escolar Indígena: diversidade sociocultural indígena ressignificando a escola, sobre a estruturação da rede física das escolas indígenas, destaca-se: “[...] quando da edição do Decreto 26/91, as escolas indígenas já apresentavam um déficit de estrutura física para seu funcionamento, e a carência de prédios escolares só veio a aumentar, com a expansão dessas escolas em número de matrículas" (Brasil, 2007, p. 82). Para garantir a qualidade da oferta da EEI em relação à infraestrutura escolar, a publicação aponta, dentre os objetivos específicos para a estruturação da rede física das escolas indígenas: 
- Reduzir o déficit de prédios escolares nas comunidades indígenas, aportando recursos técnicos e financeiros para Secretarias de Educação executarem ações de construção, ampliação, reforma e aquisição de equipamentos para as escolas indígenas.

- Estruturar a rede das escolas indígenas, levando em consideração as concepções de edificação, ocupação espacial e condições socioambientais próprias de cada povo indígena.

- Assessorar tecnicamente as Secretarias de Educação para garantir a participação das comunidades na definição dos padrões arquitetônicos adequados às suas realidades socioculturais e ambientais.

- Fomentar a flexibilização das estruturas destinadas a prédios escolares de modo a atender as especificidades culturais e ecológicas de cada povo indígena (Brasil, 2007, p. 82).

A infraestrutura escolar ainda se põe como desafio para o Ministério da Educação, pois, ao se considerar a história da oferta de educação escolar para os povos indígenas, constata-se que,

Foram construídos prédios escolares que representavam a intenção dominadora e assimiladora da escola sobre as culturas indígenas com construções que não dialogavam com os conhecimentos e as concepções indígenas sobre edificações e ocupação espacial. Desse modo, é responsabilidade do MEC fomentar o diálogo intercultural propositivo entre as comunidades e as instituições executoras para que as propostas de infraestrutura escolar sejam condizentes com as perspectivas indígenas e suas realidades ecológicas, garantindo, com isso, resultados efetivos na aplicação dos recursos públicos (Brasil, 2007, p. 83).

A situação precária e a falta de escolas para a oferta de educação escolar indígena é uma realidade extensiva a toda a educação básica pública, infelizmente. Quanto à qualidade da educação, Dourado, Oliveira e Santos (2007) incluem, nas dimensões intraescolares, a necessidade de existência de espaços, tais como bibliotecas e laboratórios, áreas de refeições e recreação, por exemplo.

A Resolução CNE/CEB no 5, de 22 de junho de 2012 (Conselho Nacional da Educação, 2012), define as Diretrizes Curriculares Nacionais especificamente para a Educação Escolar Indígena na Educação Básica. Nos princípios dessa educação,

Art. $6^{\circ}$ Os sistemas de ensino devem assegurar às escolas indígenas estrutura adequada às necessidades dos estudantes e das especificidades pedagógicas da educação diferenciada, garantindo laboratórios, bibliotecas, espaços para atividades esportivas e artístico-culturais, assim como equipamentos que garantam a oferta de uma educação escolar de qualidade sociocultural (Conselho Nacional de Educação, 2012). 
Espaços Escolares Indígenas no Brasil

Mais recentemente, a publicação do material Por uma Educação Descolonial L Libertadora: manifesto sobre a educação escolar indígena no Brasil (Altini et al., 2014) demonstra que os debates em torno do assunto têm avançado, inclusive por iniciativa de representantes diversos da sociedade civil organizada. O referido texto traz importantes elementos para a discussão aqui levantada, entre eles a problematização do fato de que, apesar dos avanços conquistados com a aprovação de leis que defendem a consideração das especificidades culturais no campo educacional, bem como as iniciativas de governos municipais, estaduais e nacional no sentido de cumpri-las, a realidade vivida pelos grupos indígenas brasileiros ainda continua precária no que diz respeito ao pleno exercício de seu direito à educação.

\section{Intervenções Arquitetônicas Voltadas aos Espaços Escolares Indígenas no Brasil}

Constatamos, a partir da análise de diferentes fontes (documentos, legislação, projetos arquitetônicos e publicações na mídia), que a precariedade presente nos espaços escolares indígenas se faz notar atualmente em diferentes planos: a) no plano da infraestrutura das construções, que são inadequadas no que diz respeito aos parâmetros técnicos divulgados pelo próprio Ministério da Educação (ventilação, iluminação, conforto visual etc.), mas também em relação àqueles convencionados pelas comunidades nas quais foram instaladas, tendo em vista suas identidades culturais; b) no plano das práticas e dos processos reconhecidos como pedagógicos, já que muitas vezes os espaços escolares inseridos nessas comunidades não são pensados levando em conta as especificidades que cercam as formas de aprendizagem e as experiências de cada etnia. Isso pode ser claramente observado nas intervenções arquitetônicas e espaciais realizadas em agrupamentos indígenas, com a inserção de modelos de escola, habitação, postos de saúde e módulos sanitários que se repetem em territórios de diferentes etnias, desconsiderando as particularidades de cada cultura e mesmo de cada região (no tocante à qualidade do ambiente construído, como a adequação bioclimática dessa arquitetura) ${ }^{1}$.

O Censo Escolar de 2005 apresentou dados sobre a infraestrutura das escolas indígenas. Segundo o censo, grande parte das escolas não possuía espaço próprio, havendo, nesse caso, o desenvolvimento de atividades em ambientes inadequados, o que revela "[...] a precariedade das condições em que o ensino é oferecido nas aldeias” (Grupioni, 2015). Ao investigar com mais profundidade a qualidade e a variedade dos espaços disponíveis nas escolas indígenas, mais uma vez se ressalta que a realização de atividades pedagogicamente diversificadas tem sido insuficiente, tanto relacionadas à cultura em questão, quanto voltadas à conexão com o restante do mundo, especificamente por meio da informática e de tecnologias digitais. Ainda que tenham ocorrido grandes conquistas voltadas ao reconhecimento do direito a uma educação que respeite as especificidades culturais, mesmo assim faltam mecanismos que possibilitem vivenciá-las na prática. Somado a isso, acredita-se que

\footnotetext{
208 Educação \& Realidade, Porto Alegre, v. 43, n. 1, p. 201-222, jan./mar. 2018.
} 
a discussão sobre os espaços em que essa educação diferenciada pode ocorrer ainda são incipientes.

Um grande desafio posto reside na existência de múltiplos grupos indígenas, cada qual com especificidades relacionadas aos processos pedagógicos, à visão de mundo e às vivências socioculturais e ambientais. Disso decorre a necessidade de aprofundar o conhecimento da equipe que desenvolverá o projeto arquitetônico da escola acerca dos espaços onde a aprendizagem acontece, considerando a contextualização em que os conteúdos são abordados em cada etnia. Nesse sentido, vê-se como pertinente que o projeto arquitetônico seja embasado nas diretrizes e nos processos educativos definidos pelo projeto pedagógico de cada escola, a partir do protagonismo e da autonomia da comunidade indígena na elaboração de tal documento.

Sobre esse ponto, Brand e Calderoni (2012) destacam a necessidade de a escola contemplar a visão de mundo indígena, que compreende o todo de uma forma mais integrada e culturalmente contextualizada, relacionando o conhecimento à espiritualidade. Essa visão se contrapõe ao modo de organização do conhecimento nas escolas convencionais, que ocorre em disciplinas específicas, resultando, por vezes, em conhecimentos pontuais, fragmentados e descontextualizados. Somado a isso, os autores ressaltam ainda que os processos de ensino e aprendizagem indígenas estão inseridos em sistemas de trocas e de reciprocidade, estabelecendo relações dialógicas comunitárias e interpessoais - reforçando, assim, o papel da família extensa para o aprendizado.

Partindo das especificidades acima elencadas, relacionadas ao processo de aprendizado dentro de aldeias indígenas, coloca-se em questionamento o papel da arquitetura escolar como possibilitadora de experiências significativas e contextualizadas às vivências da comunidade. Existem vários estudos sobre a importância do espaço escolar no processo de aprendizado nas sociedades modernas ocidentais, considerando, neles, os códigos de conduta, as formas de organização e o uso desses espaços. Incluem-se, nesses estudos, também os desafios impostos pela jornada ampliada ou educação integral (Frago; Escolano, 2001; Hertzberger, 1996; Kowaltowski, 2011; Silva; Cristofoli; Zanin, 2012; Zanin et al., no prelo; Silva; Zanin, 2015; entre outros). Contudo, poucas reflexões podem ser encontradas acerca do espaço escolar indígena, especialmente no Brasil. Em contrapartida, existem críticas relacionadas à precariedade desse espaço, bem como manifestações de indivíduos indígenas de diferentes etnias que ressaltam a importância de haver uma escola que contemple e possibilite, espacialmente, aprendizados voltados às vivências culturais (Tassinari, 2008; Bonin, 2008; Silva, 2014).

Essa realidade nos suscita reflexões sobre a complexidade de fatores a serem considerados a fim de se alcançar um resultado satisfatório no desenvolvimento de projetos arquitetônicos para escolas indígenas. A escuta atenta às comunidades mostra-se como uma ação fundamental, a fim de que se revelem as atividades abarcadas pelos processos pedagógicos, bem como as características dos espaços que irão acolher 
Espaços Escolares Indígenas no Brasil

a comunidade escolar. A partir disso, poder-se-á detalhar o programa arquitetônico almejado para a escola em questão. Esse programa, denominado no meio arquitetônico como programa de necessidades, é o ponto inicial para o desenvolvimento de um projeto. Kowaltowski (2011) sugere que o desenvolvimento do programa de necessidades seja valorizado com o intuito de melhorar o processo de projeto, realizando levantamento de dados, problemas e soluções de forma participativa junto aos futuros usuários.

É necessário contar com adequadas oportunidades de diálogo, buscando contemplar, de forma efetiva, a participação da comunidade interessada. Também podem ser identificados recursos de representação que facilitem a comunicação e a interação, tais como maquetes de estudos manuseáveis que sejam utilizadas em diferentes etapas do processo de projeto. Malnar e Vodvarka (2013) apresentam exemplos de desenvolvimento de projetos arquitetônicos junto a comunidades indígenas da América do Norte, assinalando experiências em equipes compostas por arquitetos, antropólogos e indígenas. Os autores destacam a relevância, no período inicial do projeto, de vencer as dificuldades de comunicação entre as partes, o que pode levar algum tempo, mas que também diminuirá a possibilidade de frustrações e de conflitos. No caso de projetos de arquitetura escolar, outros profissionais também podem compor a equipe, trazendo aportes da área da educação e da psicologia. A composição de equipes multidisciplinares foi utilizada pelo Ministério da Educação na definição de parâmetros para escolas de educação infantil (Brasil, 2006), indicando a necessidade de conhecer e de atender às especificidades do público usuário desses espaços.

Malnar e Vodvarka (2013) consideram que, ao projetar para distintas culturas, os arquitetos precisam se engajar em processos completamente diferentes do padrão de mercado, alterando, inclusive, suas definições de sucesso no projeto. A escuta atenta à comunidade indígena, somada à sensibilidade para responder às suas expectativas, mesmo que leve mais tempo, é crucial para o resultado do projeto. Nesse contexto, o arquiteto pode assumir o papel de um facilitador, buscando compreender e integrar, no projeto, distintas necessidades que precisam estar expressas no espaço físico. Os autores destacam ainda a possibilidade, na América do Norte, de tais profissionais serem indígenas ou não indígenas. No Brasil, a situação ainda é diferente, pois os projetos escolares são desenvolvidos por arquitetos não indígenas, que pertencem aos órgãos públicos ou são contratados. Apesar disso, o incentivo do acesso indígena à educação superior pode modificar esse quadro.

Soares (2010) ressalta que, ao trabalhar com projetos de assistência a comunidades indígenas, nas quais o processo de tomada de decisão é coletivo, faz-se necessário ter tempo qualificado para o diálogo em direção a uma solução que atenda às expectativas e às demandas do grupo. Contudo, o cenário de desenvolvimento e execução de projetos supõe prazos preestabelecidos, os quais acabam marcando o ritmo dos diálogos. Além disso, as comunidades ficam desmotivadas quando submetidas a processos de negociação infrutíferos, o que dificulta novos 
diálogos. Por esse motivo, em cada processo de intervenção, é preciso conquistar a confiança da comunidade, a fim de que se consiga o envolvimento e a participação do coletivo.

Encontramos iniciativas, como o Marco dos Povos Indígenas do Rio Grande do Sul (Rio Grande do Sul, 2012), que buscam contemplar o direito à diversidade étnica por meio de processos de consulta prévia, livre e informada, conforme estabelecido pela legislação em vigor ${ }^{2}$, reconhecendo as identidades e as culturas dos povos indígenas e sua ligação com o entorno ambiental por eles habitado. No documento citado, consta a descrição das reuniões com as comunidades que receberiam melhorias nos espaços escolares, além dos critérios para a escolha de tais comunidades. A partir das consultas, os projetos apresentados passariam a ser adaptados para atender às solicitações de cada comunidade. No entanto, o documento ressalta o desafio colocado pelas comunidades indígenas no sentido de "[...] antecipar a discussão sobre a proposta pedagógica para a escola, a ser construída em cada espaço, garantindo a participação de todos os envolvidos, antes mesmo da execução das obras" (Rio Grande do Sul, 2012, p. 12).

Essa preocupação demonstrada reflete o que temos argumentado, apoiadas em Frago e Escolano (2001), que consideram o espaço escolar como parte do currículo. Sob esse ponto de vista, o espaço escolar deveria ser concebido a partir das intenções pedagógicas, respeitando os usos pretendidos com sua configuração, forma, distribuição e suas interconexões, inclusive com os ambientes externos.

Em Silva (2014), há depoimentos de representantes indígenas que enfatizam a necessidade de o espaço escolar permitir usos culturais, encontros e atividades que vão além daqueles comumente realizados em escolas da rede pública, uma vez que a comunidade toda participa da escola. Nesse sentido, faltam espaços específicos para abrigar a comunidade e suas atividades cotidianas, que são parte do aprendizado, uma vez que a educação é algo contínuo durante a vida, reforçada pelas trocas entre distintas gerações. As falas dos professores indígenas retratam o desejo de contemplar, no espaço escolar, os costumes e as tradições, bem como a relação com o ambiente natural - o sol, a chuva, o fogo, a terra, a mata - como integrantes do ensino escolar. Em virtude disso, reclamam por uma escola que ainda não existe.

Contrapondo-se a essa complexidade e profundidade almejada de que o espaço escolar abranja as especificidades culturais, há os projetos-padrão, ou projetos-modelo, os quais, desconsiderando a legislação referente aos direitos indígenas, reproduzem a mesma solução arquitetônica em diferentes contextos culturais, ambientais e climáticos. Atualmente, encontram-se ainda projetos-padrão do Fundo Nacional de Desenvolvimento da Educação (FNDE), com indicação para inserção em comunidades indígenas (FNDE, 2015). Apresentamos, a seguir, uma figura ilustrando um desses projetos, o qual, conforme instruções publicadas, também é indicado para ser construído em comunidades quilombolas:

Educação \& Realidade, Porto Alegre, v. 43, n. 1, p. 201-222, jan./mar. 2018. 


\section{Figura 1 - Projeto de Escola com uma Sala de Aula Padrão FNDE com Indicação para Escolas Indígenas e Quilombolas}

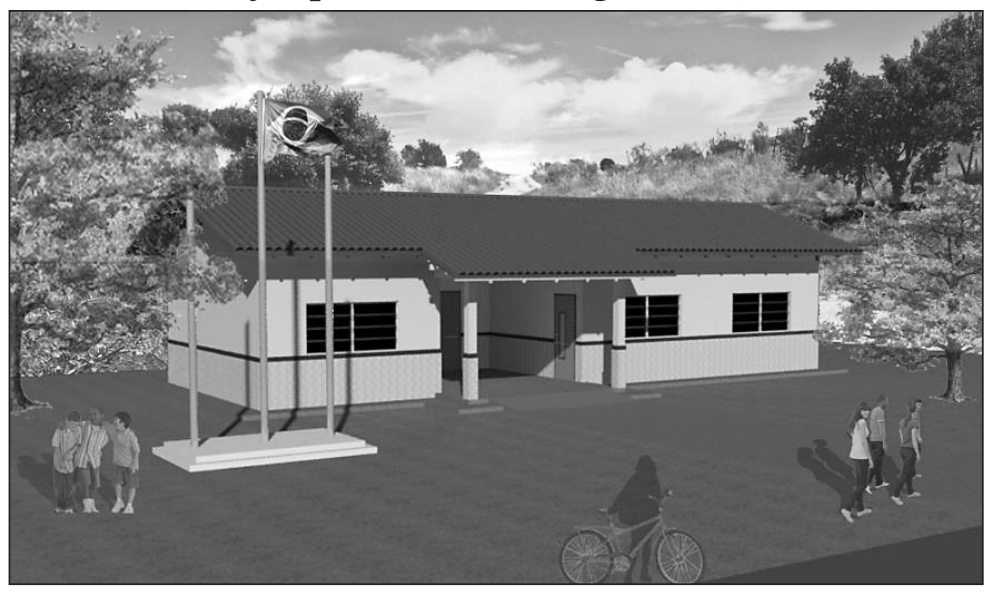

Fonte: Fundo Nacional do Desenvolvimento da Educação (2015).

Além desse, podemos destacar o modelo de escola-padrão do FNDE, com seis salas de aula, sendo utilizado para a construção de escolas indígenas em diferentes regiões do país, ainda que seja ilustrado com uma inserção urbana, como se pode verificar na figura seguinte.

Figura 2 - Projeto de Escola-Padrão do FNDE com Seis Salas de Aula

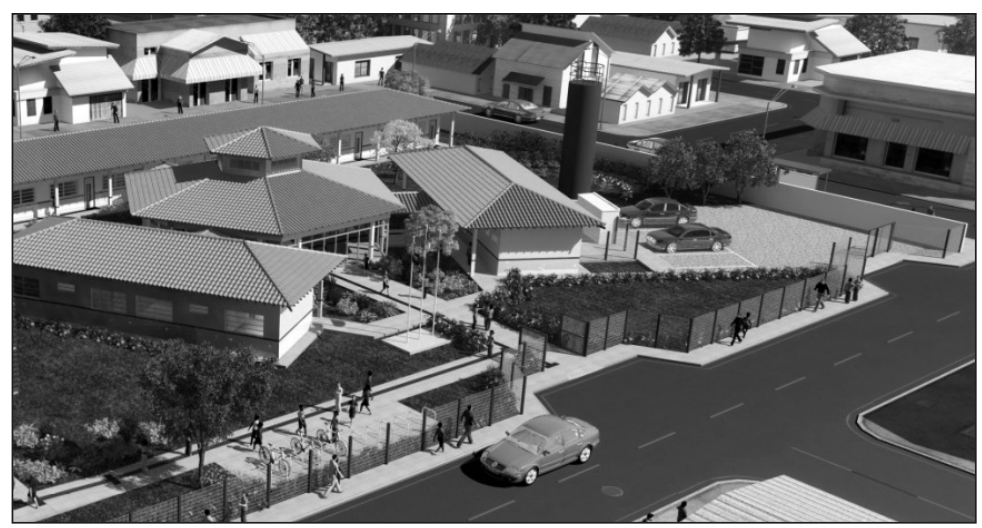

Fonte: Fundo Nacional do Desenvolvimento da Educação (2015).

Mesmo considerando que a implementação de tais projetos represente um grande avanço em direção à qualidade da educação indígena frente à precariedade dos espaços existentes, cabe questionar o seguinte: como é possível considerar que uma arquitetura idêntica aplicada a várias etnias indígenas seja capaz de contemplar a diversidade ou, mais a fundo, as especificidades culturais e o contexto geral em que se inserem? 
Vemos, em iniciativas habitacionais, esse tipo de equívoco se materializar nas aldeias indígenas do território nacional. Isso ocorre por intermédio de projetos-padrão que buscam adequar minimamente propostas prévias de habitação de interesse social, ou mesmo propostas específicas de moradia indígena projetadas para determinada etnia sendo construídas em territórios de outra etnia (Zanin, 2006; Carrinho, 2010; Carvalho, 2013). O resultado disso é uma construção que não contempla as especificidades culturais, ficando, em muitos casos, abandonada ou tendo um uso restrito, o que acarreta em um questionamento sobre a eficácia do investimento público voltado a essas comunidades. Nessas situações, os próprios indígenas reclamam ${ }^{3}$ da interferência negativa provocada pela inserção de construções que desconfiguram a distribuição espacial tradicional das moradias, as quais seguem relações internas de sociabilidade e conexão com o ambiente natural e produtivo. A situação se agrava ainda mais ao aprofundarmos questões relacionadas à dificuldade de apropriação dos modelos por não haver uma maior aproximação de aspectos culturais, técnicos e cosmológicos.

Em Zanin (2006), são apresentados aspectos simbólico-culturais que proporcionam uma maior compreensão do significado atribuído às construções autóctones da etnia Mbyá Guarani, que representam uma conexão com sua cosmologia e sua visão de mundo. O próprio processo construtivo tem o papel de fortalecer a cultura e as redes de parentesco, fomentando uma economia interna de reciprocidade. Os materiais utilizados são elementos naturais que contêm significado simbólico a determinar sua escolha, correspondendo à proteção oferecida pelas suas divindades. Somada a isso, a forma da construção, sua orientação solar, localização e distribuição espacial também fazem parte de um sistema de símbolos com significado dentro da cultura, proporcionando, dessa forma, a vivência de seu modo de vida tradicional. Por todos esses aspectos, a autora fortalece o questionamento sobre a inserção de habitações fora do sistema construtivo tradicional da etnia, indicando a necessidade de se buscar formas de continuidade das construções autóctones, o que somente é possível se houver o acesso a ambientes naturais equilibrados que contenham os elementos que permitem o modo de vida Guarani.

A situação descrita acima exemplifica a complexidade simbólica que envolve o desenho de novas escolas indígenas, a fim de que elas sejam mais adequadas às etnias nas quais estarão inseridas. Nesse tocante, ressalta-se a necessidade de desenvolver projetos específicos, os quais, em alguns casos, exigirão processos de viabilização diferentes dos previstos pela gestão pública, não correspondendo, portanto, a projetos-padrão, mas buscando contemplar as necessidades apresentadas por meio dos projetos pedagógicos desenvolvidos por cada etnia. Talvez algumas etnias desejem utilizar suas próprias técnicas construtivas e, por causa disso, outras formas de apoio serão necessárias para viabilizar essas novas construções. Nesse caso, é preciso ser criativo para respeitar a diversidade e as especificidades, fazendo algumas exceções 
a fim de garantir a inclusão, a partir do reconhecimento dos saberes autóctones. Isso significa que, em se tratando dos espaços construídos para atender à legislação que defende os direitos indígenas a uma educação específica, pode ser necessário viabilizar a utilização de materiais, técnicas, sistemas construtivos, bem como soluções funcionais não convencionais, relativizando inclusive os processos que os possibilitam. Essa seria uma forma de atender à diversidade com equidade, tendo como intenção garantir uma educação efetivamente para todos (Brasil, 2007).

Para ilustrar a necessidade e a factibilidade de se desenvolverem projetos específicos, destacamos o exemplo da solução arquitetônica desenvolvida e implementada nos Centros de Educação e Cultura Indígena (CECI) construídos por iniciativa da Secretaria de Educação do município, no ano de 2004, em três aldeias guarani da cidade de São Paulo (ver Figuras 3 e 4). Segundo informações disponibilizadas no portal dessa secretaria, “[...] o projeto arquitetônico de cada centro respeita as condições sócio-paisagísticas-culturais de cada aldeia, e foi elaborado juntamente com as lideranças indígenas Guarani" (Secretaria Municipal de Educação de São Paulo, 2014, grifo nosso). Consideramos esse fato extremamente relevante, uma vez que permite uma maior aproximação dos interesses de cada comunidade, o que facilita a posterior apropriação e uso dos espaços, possibilitando o correto emprego do recurso público e atendendo, ainda, às legislações em vigor voltadas à educação indígena.

\section{Figura 3 - Os CECIs Apresentam Soluções Arquitetônicas que Dialogam com a Cultura}

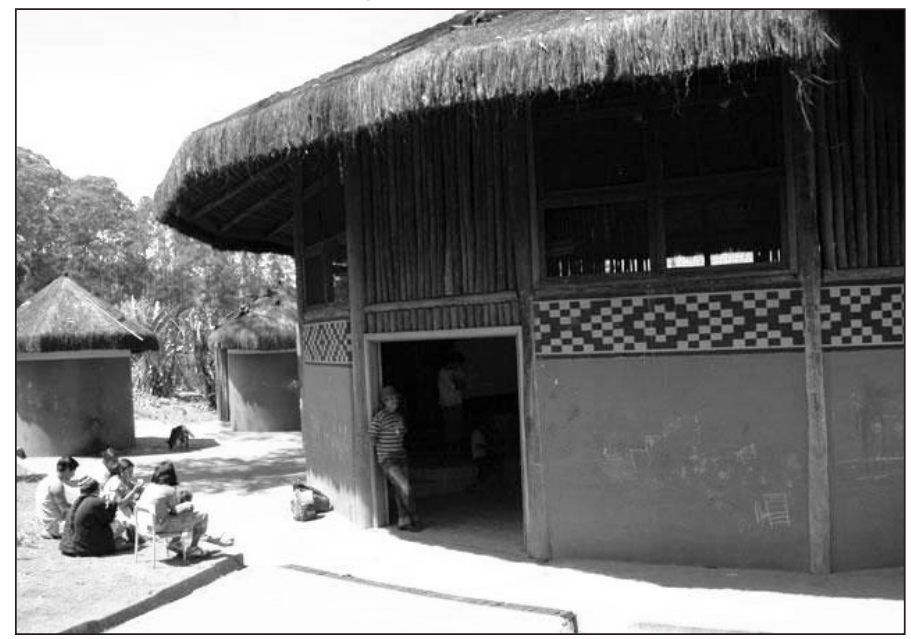

Fonte: Secretaria Municipal de Educação de São Paulo (2014). 
Figura 4 - CECI da Aldeia Krukutu

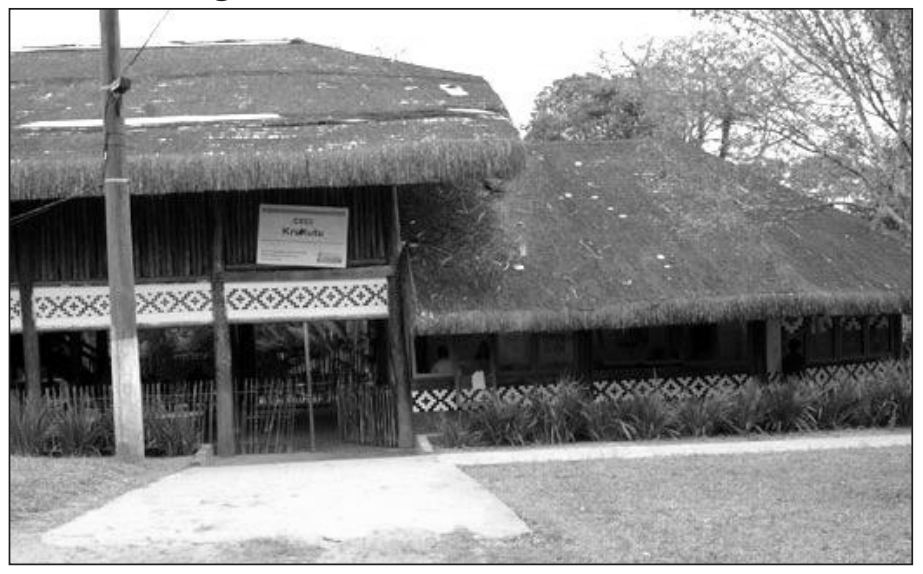

Fonte: Secretaria Municipal de Educação de São Paulo (2014).

Os CECIs possibilitam a continuidade do convívio social, permitindo que as crianças menores acompanhem os irmãos mais velhos e que as mães acompanhem seus bebês. Além disso, os processos educativos não se restringem à sala de aula: "As atividades pedagógicas acontecem em todos os espaços da aldeia, como na casa de reza ${ }^{4}$, na mata e nos espaços de uso coletivo do CECI" (Secretaria Municipal de Educação de São Paulo, 2014. A secretaria destaca, ainda, a diferenciação do calendário e das rotinas escolares, os quais foram elaborados conjuntamente com a comunidade, respeitando os ciclos naturais e as tradições culturais. Consideramos que, quando comparada com a realidade encontrada em outras aldeias, a experiência de mais de dez anos dos CECIs apresenta avanços em direção à qualificação dos espaços escolares indígenas, contribuindo, assim, para a afirmação da identidade étnica.

A construção dos CECIs em São Paulo é contemporânea à construção de algumas escolas indígenas com desenho específico pelo estado de Santa Catarina em aldeias Guarani, Kaingang e Xokleng. Tais edificações são decorrentes das mudanças legislativas e de um cenário favorável ao desenvolvimento de projetos arquitetônicos diferenciados. Dessas escolas, destacamos a Escola Indígena de Educação Básica Cacique Vanhkre (EIEB Cacique Vanhkre), devido à participação da comunidade escolar na definição do desenho arquitetônico (Zanin; Dill, 2016). Nesse processo, a equipe de projeto estava aberta à compreensão das necessidades da comunidade escolar, que, por sua vez, conseguiu comunicar suas motivações, traduzindo-as conjuntamente em conceitos arquitetônicos.

Como resultado disso, Zanin e Dill (2016) destacam que foi construída uma escola que se tornou referência para a educação escolar indígena, já que contempla e facilita a identificação dos usuários devido à presença de formas e de elementos relacionados ao seu modo de vida. O ginásio de esportes e o Centro Cultural apresentam soluções zoomorfas, inspiradas em animais representativos para a etnia. A edificação 
Espaços Escolares Indígenas no Brasil

que contém as salas de aula, a área administrativa, a biblioteca, os refeitórios e os sanitários, com desenho circular, remete às formas de organização de aldeias do tronco linguístico Jê, em que a casa dos homens fica localizada no centro (Novaes, 1983). Segundo o memorial descritivo do projeto, essa edificação expressa aspectos míticos e filosóficos da cultura Kaingang. A construção inicial proporcionava o uso do fogo de chão junto às salas de aula, e o pátio interno era em chão batido, assim como a sala de artesanato. Zanin e Dill (2016) constataram que, posteriormente, algumas dessas características foram alteradas em reformas de manutenção, e o desgaste dos materiais impediu o uso de alguns espaços, como o Centro Cultural.

\section{Figura 5 - Ginásio de Esportes da EIEB Cacique Vanhkre, em} Forma de Tatu

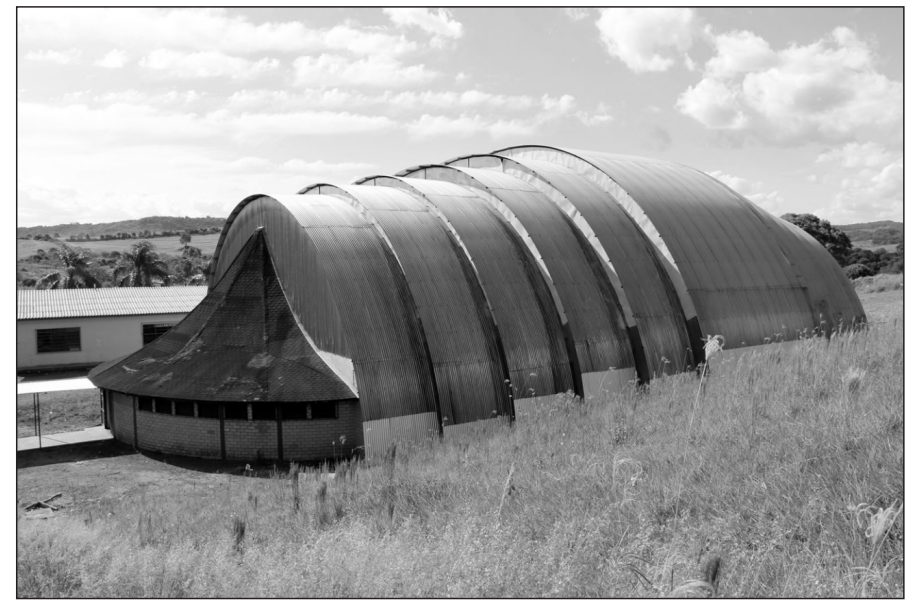

Fonte: Zanin e Dill (2016).

Figura 6 - EIEB Cacique Vanhkre, em Formato Circular

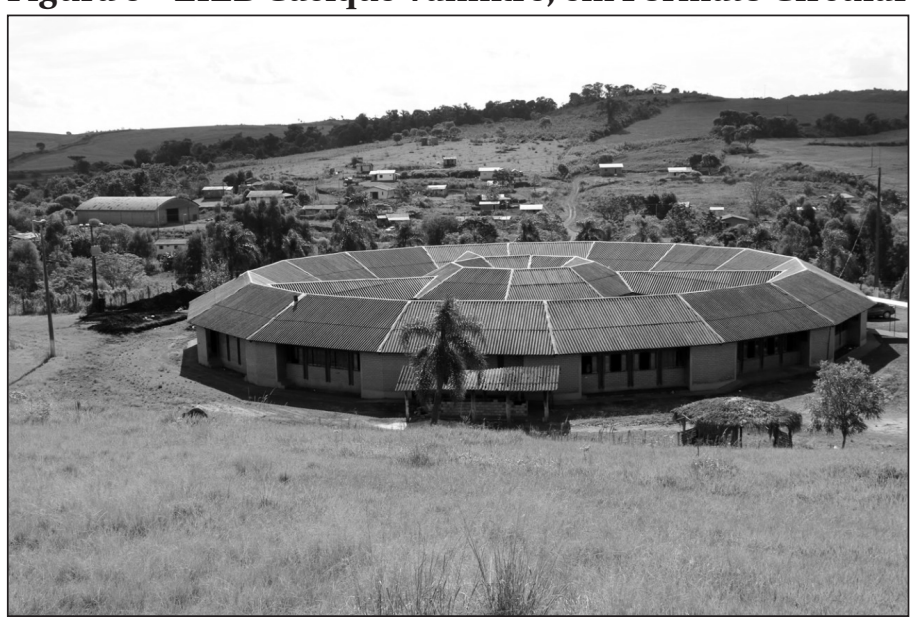

Fonte: Zanin e Dill (2016). 
Figura 7 - Centro Cultural da EIEB Cacique Vanhkre, em Forma de Tartaruga

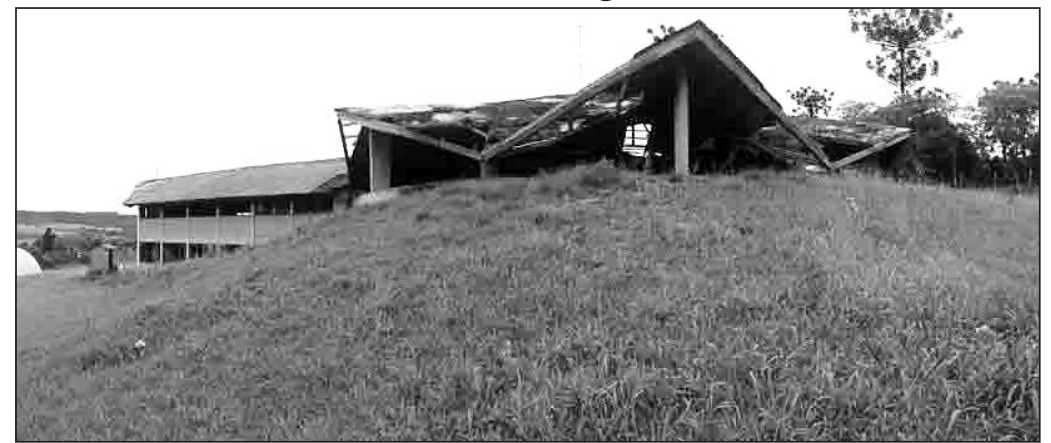

Fonte: Zanin e Dill (2016).

Existem exemplos mais recentes de projetos arquitetônicos para escolas indígenas no Brasil desenvolvidos com a participação das comunidades, mas também é recorrente a opção pela inserção de projetos-modelo, em alguns casos, como uma escolha dos próprios indígenas em busca de uma educação com a mesma qualidade que as demais escolas públicas. Conforme argumentado anteriormente, entendemos que o espaço escolar é parte integrante do currículo e que a legislação deve favorecer que sejam respeitadas as perspectivas indígenas na definição desses espaços, sempre de acordo com o interesse de cada comunidade. A partir de nossos estudos, no contexto geral das escolas indígenas brasileiras, observamos a necessidade de aprimorar as ações para que os espaços físicos escolares traduzam as reais necessidades procedentes dos processos pedagógicos de cada etnia.

\section{Considerações Finais}

A escola indígena, como um espaço de interface cultural, tem o desafio de acolher os conhecimentos indígenas, possibilitando sua continuidade e valorização, permitindo, ainda, o acesso aos conhecimentos proporcionados pelo avanço da ciência que são necessários para o diálogo das comunidades nativas com a sociedade envolvente. Nesse sentido, a escola indígena tem o desafio de responder à complexidade presente nesse espaço, que não só é específico e diferenciado, como também abriga a interculturalidade presente hoje nas comunidades indígenas. A escola indígena representa, nesse contexto, o local de diálogo, expresso não somente pelo bilinguismo, como também pelos objetivos dos sujeitos que a frequentam, qual seja: a defesa de sua identidade e autonomia.

A partir de nossos estudos, podemos perceber que a realidade das escolas indígenas, até este momento, reflete, em grande parte, as dificuldades encontradas em qualificar a educação pública, ainda que as iniciativas em direção ao atendimento dos direitos indígenas estejam aumentando gradativamente. É possível notar um movimento em bus- 
ca da qualificação dos espaços com a reforma e a construção de escolas; contudo, ainda está distante do atendimento às especificidades de cada contexto e cultura. Nesse tocante, a diversidade étnica e cultural encontrada no Brasil, a qual, como mencionado na introdução deste artigo, pode ser considerada uma de suas grandes riquezas, apresenta-se também como um grande desafio.

Em nossas pesquisas, temos encontrado iniciativas de desenvolvimento de projetos junto a comunidades indígenas de outros países que foram capazes de alcançar resultados positivos (Malnar; Vodvarka, 2013). Alguns desses diálogos levaram anos até sua materialização em espaços escolares, possibilitando a compreensão efetiva das especificidades simbólicas e culturais, o que só foi possível devido à autonomia das comunidades na gestão dos recursos. A valorização de processos de projeto que integrem a comunidade escolar indígena, respeitando e articulando distintas concepções de tempo e formas de tomada de decisão, é outro desafio presente.

No Brasil, a educação é um direito público, e os espaços escolares indígenas se inserem nas pautas e nas agendas das políticas públicas. Contudo, é preciso avançar no desenho e na implementação de políticas públicas para espaços escolares indígenas diferenciadas e adequadas às necessidades dessas populações. Nesse sentido, necessitamos investir em estudos de análise dessas políticas, como destaca Souza (2006, p. 40), identificando, de forma clara, o problema a ser resolvido, politics, polity, “[...] e nas instituições/regras que irão modelar a decisão e a implementação da política pública”.

No lugar de ações governamentais essencialmente assistencialistas e tutelares, vemos a necessidade de uma inclusão educacional, social e, sobretudo, política. Um passo fundamental para vencer esses desafios é assumirmos, como sociedade, o compromisso de criar condições de diálogo para que as comunidades indígenas sejam protagonistas nos processos decisórios. Uma inclusão mais plena passa por aí. Percebemos, portanto, a necessidade de visibilizar a diferença, valorizando e oportunizando a presença desses sujeitos e de suas culturas em diferentes ambientes educacionais (da educação básica ao ensino superior).

Recebido em 26 de fevereiro de 2016 Aprovado em 07 de agosto de 2017

\section{Notas}

1 Essa falha recorrente se espelha no fato de os povos indígenas serem chamados genericamente de índios, o que encobre e desconsidera a diversidade étnica existente (Bergamaschi, 2005).

2 Especialmente as Diretrizes Curriculares Nacionais para a Educação Escolar Indígena e o Referencial Curricular Nacional para Escolas Indígenas/MEC de 2005 (Brasil, 2005). 
3 Fala de representante indígena da comunidade de Kandoia, que relatou em evento público a surpresa que teve ao retornar à sua comunidade e verificar que a aldeia indígena se transformara em "bairro indígena", devido à inserção de moradias provenientes do programa de habitação social Minha Casa, Minha Vida. Para maior aprofundamento sobre esse programa nas aldeias, ver Carrinho (2010) e Carvalho (2013).

4 Espaço cerimonial guarani (Opy).

\section{Referências}

ALTINI, Emilia et al. (Org.). Por uma Educação Descolonial e Libertadora: manifesto sobre a educação escolar indígena no Brasil. Brasília: CIMI, 2014. Disponível em: <http://cimi.org.br/pub/MS/escolas/ManifestoEduca.pdf >. Acesso em: 31 dez. 2014.

ARROYO, Miguel. Currículo, Território em Disputa. Petrópolis: Vozes, 2012.

ARRUTI, José Maurício Andion. A Emergência dos “Remanescentes": notas para o diálogo entre indígenas e quilombolas. Mana, Rio de Janeiro, v. 3, n. 2, out. 1997. Disponível em: <http://www.scielo.br/scielo.php?script=sci_arttext\&pid=S0104-93131997000200001\&lng=en\&nrm=iso >. Acesso em: 1 jan. 2015.

BERGAMASCHI, Maria Aparecida. Nhembo'e: enquanto o encanto permanece! Processos e práticas de escolarização nas aldeias Guarani. 2005. 272 f. Tese (Doutorado em Educação) - Programa de Pós-Graduação em Educação, Faculdade de Educação, Universidade Federal do Rio Grande do Sul, Porto Alegre, 2005.

BONIN, Iara. Educação Escolar Indígena e Docência: princípios e normas na legislação em vigor. In: BERGAMASCHI, Maria Aparecida (Org.). Povos Indígenas \& Educação. Porto Alegre: Mediação, 2008. P. 95-107.

BOTO, Carlota. A Educação Escolar como Direito Humano de Três Gerações: identidades e universalismos. Educação \& Sociedade, Campinas, v. 26, n. 92, p. 777-798, 2005.

BRAND, Antônio Jacó; CALDERONI, Valéria Aparecida Mendonça de Oliveira. Território e Saberes Tradicionais: articulações possíveis no espaço escolar indígena. Práxis Educativa, Ponta Grossa, v. 7, p. 133-153, dez. 2012. Disponível em: <http://www.redalyc.org/articulo.oa?id=89425835007>. Acesso em: $31 \mathrm{dez}$. 2014.

BRASIL. Constituição da República Federativa do Brasil: promulgada em 5 de outubro de 1988. Organização do texto: Juarez de Oliveira. São Paulo: Saraiva, 1990. (Série Legislação Brasileira).

BRASIL. Decreto ${ }^{\circ} 26$, de 4 de fevereiro de 1991. Dispõe sobre a Educação Indígena no Brasil. Diário Oficial da União, Brasília, DF, 5 fev. 1991.

BRASIL. Lei no 9.394, de 20 de dezembro de 1996. Estabelece as diretrizes e bases da educação. Diário Oficial da União, Brasília, DF, 23 dez. 1996.

BRASIL. Ministério da Educação. Secretaria de Educação Básica. Parâmetros Básicos de Infraestrutura para Instituições de Educação Infantil. Brasília: MEC/ SEB, 2006.

BRASIL. Ministério da Educação. Secretaria de Educação Continuada, Alfabetização e Diversidade. Educação Escolar Indígena: diversidade sociocultural indígena ressignificando a escola. Cadernos SECAD 3. Brasília: SECAD/MEC, 2007. 
Espaços Escolares Indígenas no Brasil

BRASIL. Decreto n 6.861 , de 27 de maio de 2009. Dispõe sobre a Educação Escolar Indígena, define sua organização em territórios etnoeducacionais e dá outras providências. Diário Oficial da União, Brasília, DF, 28 maio 2009.

BRASIL. Lei no 13.005, de 25 de junho de 2014. Aprova o Plano Nacional de Educação - PNE e dá outras providências. Diário Oficial da União, Brasília, DF, 26 jun. 2014.

BRASIL. Ministério da Educação. Plano Nacional de Educação. Brasília: Inep, 2014.

CARRINHO, Rosana Guedes. Habitação de Interesse Social em Aldeias Indígenas: uma abordagem sobre o ambiente construído Mbyá-guarani no litoral de Santa Catarina. 2010. 206 f. Dissertação (Mestrado em Arquitetura e Urbanismo) - Centro Tecnológico, Programa de Pós-Graduação em Arquitetura e Urbanismo, Universidade Federal de Santa Catarina, Florianópolis, 2010.

CARVALHO, Bárbara Moraes de. Intervenções Habitacionais em Comunidades Tradicionais: uma solução ou um problema? In: ENCONTRO NACIONAL DA ANPUR, 15., 2013, Recife. Anais... Recife: 2013. Disponível em: <http://unuhospedagem.com.br/ revista/rbeur/index.php/anais/article/viewFile/4530/4399>. Acesso em: 22 maio 2014.

CONFERÊNCIA DE EDUCAÇÃO ESCOLAR INDÍGENA, 1., 2009, Luziânia, GO.

CONFERÊNCIA NACIONAL DE EDUCAÇÃO, 2014, Brasília. Documento - Referência. Elaborado pelo Fórum Nacional de Educação. Brasília: Ministério da Educação, Secretaria Executiva Adjunta, [2013].

CONSELHO NACIONAL DE EDUCAÇÃO. Câmara de Educação Básica. Resolução CEB no 3, de 10 de novembro de 1999. Fixa as Diretrizes Nacionais para o funcionamento das escolas indígenas e dá outras providências. Diário Oficial da União, Brasília, DF, 13 abr. 1999. Seção I. P. 18.

CONSELHO NACIONAL DE EDUCAÇÃO. Resolução CNE/CEB no 5, de 22 de junho de 2012. Define Diretrizes Curriculares Nacionais para a Educação Escolar Indígena na Educação Básica. Diário Oficial da União, Brasília, DF, 25 jun. 2012. Seção I. P. 7.

CURY, Carlos Roberto Jamil. A Educação Escolar, a Exclusão e seus Destinatários. Educação em Revista, Belo Horizonte, n. 48, p. 205-222, dez. 2008.

DOURADO, Luiz Fernando; OLIVEIRA, João Ferreira de; SANTOS, Catarina de Almeida. A Qualidade da Educação: conceitos e definições. Brasília: Instituto Nacional de Estudos e Pesquisas Educacionais Anísio Teixeira, 2007.

DUARTE, Clarice Seixas. Direito Público Subjetivo e Políticas Educacionais. São Paulo em Perspectiva, São Paulo, v. 18, n. 2, p. 113-118, 2004.

FRAGO, Antônio Viñao; ESCOLANO, Augustín. Currículo, Espaço e Subjetividade: a arquitetura como programa. Tradução de Alfredo Veiga-Neto. Rio de Janeiro: DP\&A, 2001.

FUNDO NACIONAL DE DESENVOLVIMENTO DA EDUCAÇÃO. Projetos Arquitetônicos para Construção. Brasília, DF, 2015. Disponível em: <http://www. fnde.gov.br/programas/par/par-projetos-arquitetonicos-para-construcao $>$. Acesso em: 23 mar. 2015.

GOMES, Nilma Lino. Diversidade e Currículo. Salto para o Futuro, Brasília, v. 17, p. 30-33, 2007.

GRUPIONI, Luis Donisete Benzi. Censo Escolar Indígena. Povos Indígenas no Brasil. Instituto Socioambiental (ISA). Disponível em: $<$ http://pib.socioambiental.org/pt/c/politicas-indigenistas/educacao-escolar-indigena/censo-escola-indigena >. Acesso em: 3 mar. 2015.

220 Educação \& Realidade, Porto Alegre, v. 43, n. 1, p. 201-222, jan./mar. 2018. 
HERTZBERGER, Herman. Lições de Arquitetura. Tradução Carlos Eduardo Lima Machado. São Paulo: Martins Fontes, 1996.

KOWALTOWSKI, Dóris. Arquitetura Escolar: o projeto do ambiente de ensino. São Paulo: Oficina de Textos, 2011.

MALNAR, Joy Monice; VODVARKA, Frank. New Architecture on Indigenous Lands. Minneapolis: University of Minnesota, 2013.

MINISTÉRIO DA EDUCAÇ̃̃O E DO DESPORTO. Secretaria de Educação Continuada, Alfabetização e Diversidade. Referencial Curricular Nacional para as Escolas Indígenas. Brasília: MEC/Secad, 2005.

NOVAES, Sylvia Caiuby (Org.). Habitações Indígenas. São Paulo: Nobel/ Editora da Universidade de São Paulo, 1983.

OLIVEIRA, Luiz Antonio de; NASCIMENTO, Rita Gomes do. Roteiro para uma História da Educação Escolar Indígena: notas sobre a relação entre política indigenista e educacional. Educação e Sociedade, Campinas, v. 33, n. 120, p. 765-781, 2012. Disponível em: <http://www.scielo.br/pdf/es/v33n120/07.pdf>. Acesso em: 21 set. 2013.

RIO GRANDE DO SUL. Programa de Apoio à Retomada do Desenvolvimento do Rio Grande do Sul. Marco dos Povos Indígenas do Rio Grande do Sul. Porto Alegre, 2012. Disponível em: <http://www.educacao.rs.gov.br/dados/ proredes_ marco_indigena_bird.pdf $>$. Acesso em: 04 mar. 2014.

SANTOS, Lucíola Licínio; NOGUEIRA, Maria Alice. Dicionário Crítico da Educação: exclusão/inclusão escolar. Presença Pedagógica, Belo Horizonte, v. 5, n. 30, p. 90-92, nov./dez. 1999.

SECRETARIA MUNICIPAL DE EDUCAÇÃO DE SÃO PAULO. Centro de Educação e Cultura Indígena (CECI). São Paulo, 2014. Disponível em: <http://portalsme. prefeitura.sp.gov.br/Main/Noticia/Visualizar/PortalSMESP/Centro-de-Educacao-e-Cultura-Indigena--CECI-1>. Acesso em: 10 maio 2015.

SILVA, Beatriz Sales da. Arrematando o Bordado, a Escola Indígena Diferenciada. In: SEMINÁRIOINFÂNCIACRIANÇAINDÍGENA, 2.,2014,SãoCarlos.Anais...SãoCarlos: 2014.P. 1-17.Disponível em:<https://infanciaindigena.files.wordpress.com/2014/10/ arrematando-o-bordado-a-escola-indc3adgena-diferenciada-beatriz-sales-da-silva.pdf $>$. Acesso em: 11 mar. 2015.

SILVA, Ivone Maria Mendes da; CRISTOFOLI, Maria Sílvia; ZANIN, Nauíra Zanardo. Contribuições da Arquitetura, da Psicologia e da Política Educacional para uma Análise do Espaço Escolar e sua Vivência pelos Sujeitos. In: ROSA, Geraldo Antônio da; PAIM, Marilane Maria Wolff (Org.). Educação Básica: políticas e práticas pedagógicas. Campinas: Mercado de Letras, 2012. P. 63-100.

SILVA, Ivone Maria Mendes; ZANIN, Nauíra Zanardo. Tempos e Espaços na Escola Contemporânea: reflexões a partir da Educação Integral. In: LOSS, Adriana Salete; SILVA, Ivone Maria Mendes (Org.). Formação Continuada de Professores e Gestores das Escolas Públicas: educação integral em jornada ampliada. 1 ed. Tubarão: Copiart, 2015. P. 85-112.

SOARES, Mariana de Andrade. É Possível Construir uma Ater Indígena Diferenciada? O caso dos guarani no estado do rio grande do sul. In: ARAÚJO, André; VERDUM, Ricardo (Org.). Experiências de Assistência Técnica e Extensão Rural junto aos Povos Indígenas: o desafio da interculturalidade. Brasília: NEAD, SAF, 2010. P. 272-292.

SOUZA, Celina. Políticas Públicas: uma revisão da literatura. Sociologias, Porto Alegre, n. 16, p. 20-45, jul./dez. 2006.

Educação \& Realidade, Porto Alegre, v. 43, n. 1, p. 201-222, jan./mar. 2018. 
TASSINARI, Antonella Maria Imperatriz. A Educação Escolar Indígena no Contexto da Antropologia Brasileira. Ilha Revista de Antropologia, Florianópolis, v. 10, n. 1, p. 217-244, ago. 2008.

VIEIRA, Sofia Lerche. Políticas e Gestão da Educação Básica: revisitando conceitos simples. Revista Brasileira de Política e Administração da Educação, Porto Alegre, v. 23, n. 1, p. 53-69, jan./abr. 2007.

ZANIN, Nauíra Zanardo. Abrigo na Natureza: construção Mbyá-Guarani, sustentabilidade e intervenções externas. 2006. 178 f. Dissertação (Mestrado em Engenharia) - Programa de Pós-Graduação em Engenharia Civil, Escola de Engenharia, Universidade Federal do Rio Grande do Sul, Porto Alegre, 2006.

ZANIN, Nauíra Zanardo et al. Tempos e Espaços na Educação Integral: estudos a partir do Programa Mais Educação. In: CRISTOFOLI, Maria Silvia; SILVA, Rodrigo Dias. Educação Integral no Brasil: dimensões, possibilidades, desafios e experiências. Erechim, RS: Gráfica Techs. No prelo.

ZANIN, Nauíra Zanardo; DILL, Fernanda Machado. Educação Escolar Indígena Manifestada em Intervenção Arquitetônica: reflexões a partir de uma escola Kaingang. In: ENCONTRO ESTADUAL DE HISTÓRIA DA ANPUH, 16., Chapecó. Anais... Chapecó: 2016.

Nauíra Zanardo Zanin é graduada em Arquiteta e Urbanismo e mestre em Engenharia Civil pela Universidade Federal do Rio Grande do Sul (UFRGS). Atualmente é doutoranda do Programa de Pós-Graduação em Arquitetura e Urbanismo da Universidade Federal de Santa Catarina (UFSC) e professora adjunta do Curso de Arquitetura e Urbanismo da Universidade Federal da Fronteira Sul (UFFS), Campus Erechim/RS.

E-mail:nauira@nauira.arq.br

Ivone Maria Mendes Silva é graduada em Psicologia e mestre em Ciências da Saúde pela Universidade Federal de Minas Gerais (UFMG), mestre em Educação pelo Centro Federal de Educação Tecnológica de Minas Gerais (CEFET/MG) e doutora em Psicologia pela Universidade de São Paulo (USP). Atualmente é professora adjunta na área de Psicologia da Educação na Universidade Federal da Fronteira Sul (UFFS), Campus Erechim/RS.

E-mail: ivone@uffs.edu.br

Maria Silvia Cristofoli é graduada em Pedagogia pela Universidade Federal do Pará (UFPA), mestre em Educação pela Universidade Federal de Santa Catarina (UFSC) e doutora em Educação pela Universidade Federal do Rio Grande do Sul (UFRGS). Atualmente é professora adjunta na área de política educacional e legislação do ensino na Universidade Federal da Fronteira Sul, Campus Erechim/RS.

E-mail: mscristofoli@uffs.edu.br 